\title{
How much captan is required for wound protection of Neonectria ditissima conidial infection in apple?
}

\author{
Monika Walter ${ }^{1}$, David W.L. Manktelow ${ }^{2}$, Fanny Le Berre ${ }^{3}$, Rebecca E. Campbell ${ }^{1}$, Lauren \\ Turner ${ }^{1}$, Lizelle Vorster ${ }^{1}$, Emma Patrick ${ }^{1}$, Ruth C. Butler ${ }^{4}$ and Grant L. Northcott ${ }^{5}$ \\ ${ }^{1}$ The New Zealand Institute for Plant and Food Research Ltd (PFR), Old Mill Road, Motueka, \\ 7198, New Zealand \\ ${ }^{2}$ Applied Research and Technologies Ltd, PO Box 3415, Hawke's Bay Mail Centre, Napier 4142, \\ New Zealand \\ ${ }^{3}$ Station d'Etudes et d'Expérimentations Fruitières de La Morinière, 37800 Saint Epain, France \\ ${ }^{4}$ PFR, Private Bag 4704, Christchurch Mail Centre, Christchurch 8140, New Zealand \\ ${ }^{5}$ Northcott Research Consultants Ltd, 23 Empire Street, Cambridge 3434, New Zealand \\ *Corresponding author: monika.walter@plantandfood.co.nz
}

\begin{abstract}
Captan (a trichloromethyl sulfenyl fungicide) is commonly used for control of Neonectria ditissima in apple. In New Zealand, picking and leaf scars are the main source of new infections. The captan concentrations required for wound protection of leaf scars, picking and rasp wounds was determined in planta. Fresh wounds, inoculated with $N$. ditissima, were sprayed with captan using a motorised knapsack (leaf scars) or hand-held spray bottles targeting the wound area (picking and rasp wounds). Captan concentrations ranged from 0 to $400 \%$ field rate $(100 \%=2 \mathrm{~kg}$ captan/ha). Wounds were sampled pre- and post-captan application for residue analyses and the remainder assessed regularly in the field for disease expression. Disease development decreased as captan concentrations increased. Approximately $2 \mu \mathrm{g}$ captan/scar (100\% field rate) was required to protect leaf scars. Four times the field rate of captan was needed for a 55 and 70\% disease reduction on picking and rasp wounds, respectively. Label-rate applications of captan controlled low incidence of $N$. ditissima leaf-scar infections in the field in autumn, but disease control of picking scars and other large wounds might be difficult to achieve.
\end{abstract}

Keywords: picking scars, leaf scars, fungicide, European canker

\section{INTRODUCTION}

European canker caused by Neonectria ditissima (syn. Nectria galligena, anamorph Cylindrocarpon heteronema) is an important tree disease in many apple-growing regions of the world, particularly those with high annual precipitation (Grove 1997). It is primarily a tree disease girdling limbs and trunks (Weber 2014). In temperate regions with high rainfall, like the Tasman region in New Zealand, picking wounds followed by leaf scars are the most important wounds in the infection and spread of Neonectria ditissima (Amponsah et al. 2015; Campbell et al. 2016; Alves \& Nunes
2017).

Captan (N-(trichloromethylthio)-cyclohex-4ene-1,2-dicarboximide) and copper fungicides are commonly used postharvest to protect apple leaf scars from $N$. ditissima (Dryden et al. 2016; Weber 2014; Swinburne 1975). Captan is a broad-spectrum protectant fungicide that was first registered in the USA in 1949 for use in fruit trees. Captan has been, and continues to be, the cornerstone in many integrated pest management programmes in conjunction with other fungicides. Captan fungicides have low acute oral and dermal toxicity, which combined 
with high efficacy, low cost and the transient nature of captan and its reactive thiol groups, have ensured its ongoing use in horticulture (Gordon 2010). Captan is widely used in New Zealand horticulture including apple production and, in 2019, captan was also registered in New Zealand for use during harvest for control of postharvest fruit rots (not $N$. ditissima).

Biological control options have failed to provide adequate control of picking and leafscar wounds (Walter et al. 2017a, b). Previously used agrichemicals, such as benzimidazoles, are no longer available and/or not recommended for use in autumn due to resistance management (Beresford 2004, Weber \& Palm 2014). Therefore, postharvest $N$. ditissima control heavily relies on inoculum removal and two to six captan or copper applications. Here we explore, in a field situation, the amount of active ingredient of captan required to protect leaf scars, picking wounds and artificial rasp wounds on two susceptible varieties of apple when inoculated with $N$. ditissima conidia. A dose-response approach has been chosen to ascertain the actual amount of active ingredient (a.i.) required for protection of these wounds to $N$. ditissima infection.

\section{MATERIALS AND METHODS}

\section{Dose-response assays}

Dose-response assays were conducted in the field by creating and inoculating fresh leaf scars, and picking and rasp wounds (Dryden et al. 2016; Walter et al. 2017b). The leaf-scar experiment was done in 2015 on 2-year-old Royal Gala' trees, and the picking and rasp wound experiment in 2018 on 5-year-old 'Scilate' trees. Both varieties are similar in susceptibility to N. ditissima and were grown on dwarfing 'M9' rootstock. Experiments were conducted at the Plant \& Food Research orchard, Whakarewa Street, Motueka.

\section{Leaf-scar experiment}

The 2-year-old 'Royal Gala' trees used had a limited number of available shoots for leaf-scar inoculations (two to three shoots per plant) and therefore large plots were used. A total of 324 trees were used (six rows $\times 54$ trees/row).
Each row was divided into six plots (nine trees per plot). There were seven treatment rates of captan (Fruitfed Captan 80 WG; with $80 \%$ active ingredient equivalent) consisting of $0,6.25$, $12.5,25,50,100$, and $300 \%$ of field rate (Table $1)$, with six replicates per treatment. These were arranged in a $7 \times 7$ Latin square design, with one randomly chosen row and one column deleted. Generally, there were two (occasionally one) buffer trees between treatment plots. In each plot, two to three shoots per tree were marked for inoculation with flagging tape. In most cases, five leaf scars on each marked shoot were created, and inoculated with a $N$. ditissima spore suspension. There were a small number of marked shoots for which there were insufficient leaves for five scars to be created. In these cases, one (one shoot), two (three shoots) or three (four shoots) leaf scars were created, depending on the available leaves.

Existing leaf scars on each tree were used as non-inoculated controls. New leaf scars were created by pulling leaves from the tree during leaf fall (24 May 2015). These were marked and brush-inoculated (20-30 $\mu \mathrm{L}$ spore suspension per wound) the following morning (25 May 2015) using freshly prepared $N$. ditissima inoculum $\left(1 \times 10^{5}\right.$ conidia/ $\left.\mathrm{mL}\right)$, as described by Walter et al. (2015, 2017b). Upon drying, spray applications were made using a Stihl back pack mist blower. The water $\mathrm{pH}$ for the fungicide dilutions was 6.3. The sprayer output restrictor was set in the \#4 position, which delivered $1.3 \mathrm{~L} /$ min as a static flow rate (fan not operating). The target spray delivery volume therefore required 72 to 76 seconds of sprayer operation per plot. Each plot was sprayed from both sides, with two sprayer passes made along each row side to fully cover all shoots and leaves. Spray delivery times were varied slightly as required to achieve even coverage without excessive runoff in plots with larger or smaller trees. The actual spray volumes applied to each treatment were recorded (Table $1)$.

Treatments were applied in order of increasing captan concentration. A separate spray mix of 10 litres was made up immediately prior to each treatment being applied, using pre-weighed 
Table 1 Captan active ingredient (ai) concentrations applied for the dose-response field study for control of Neonectria ditissima leaf-scar infections in 'Royal Gala' apple, 25 May 2015

\begin{tabular}{lcccc}
\hline $\begin{array}{l}\text { Captan \% as in } \\
\text { recommended } \\
\text { field rate }\end{array}$ & $\begin{array}{l}\text { Fruitfed Captan } \\
\text { 80 WG product } \\
\text { weight (g/100 L } \\
\text { water) }\end{array}$ & $\begin{array}{l}\text { Nominal captan } \\
\text { ai application rate } \\
(\mathrm{g} / \mathrm{ha}) \text { for trial trees } \\
\text { at } 6000 \mathrm{~m}^{3} / \mathrm{ha}^{\dagger}\end{array}$ & $\begin{array}{l}\text { Captan ai g/ha } \\
\text { equivalent for full } \\
\text { canopy dwarf trees } \\
\text { at 12,000 } \mathrm{m}^{3} / \mathrm{ha}^{\dagger}\end{array}$ & $\begin{array}{l}\text { Spray volume } \\
\text { applied (L) }\end{array}$ \\
\hline 0 (water control) & 0 & 0 & 0 & 9.5 \\
6.25 & 17 & 72 & 140 & 8.3 \\
12.5 & 35 & 156 & 310 & 8.8 \\
25 & 69 & 308 & 620 & 8.8 \\
50 & 139 & 628 & 1260 & 8.9 \\
100 & 278 & 1313 & 2630 & 9.3 \\
300 & 833 & 3554 & 7110 & 8.4 \\
\hline
\end{tabular}

₹ Trial trees were small, hence volume was adjusted to canopy size $\left(6000 \mathrm{~m}^{2} / \mathrm{ha}\right)$. The equivalent full canopy is $12,000 \mathrm{~m}^{2} / \mathrm{ha}$

chemical as shown in Table 1. The amount of captan active ingredient (ai) applied per hectare was estimated from the total plot length (43 $\mathrm{m})$ for each treatment, the chemical mixing concentration and the total quantity of spray mix applied to each treatment.

Disease assessments for symptomatic European canker lesions were carried out four times on 26 July, 16 November, 14 December 2016 and 20 January 2016 as described by Dryden et al. (2016). If one or more leaf scars showed European canker disease symptoms, the shoot was cut and removed from the orchard. At the end of the experiment all inoculated plant material was removed from the orchard. No reisolations of $N$. ditissima were undertaken as the lesions are symptomatic of the disease and sporodochia were often present.

\section{Picking and rasp wound experiment}

For this experiment 5-year old 'Scilate' trees were used, and many shoots and spurs with fruit were available as these trees were older than the 'Royal Gala' used for the leaf-scar experiment. The 'Scilate' trees were planted adjacent to the 'Royal Gala' field. A total of 216 trees were used (four rows $\times 54$ trees/row). Each row was divided into six plots. Each plot consisted of nine trees (two buffer trees/plot), with each row being a replicate and treatments assigned randomly to the six plots within each row. Treatments consisted of $0,25,50,100,200$ and $400 \%$ field rate captan (six treatments). Captan (Fruitfed Captan 80 WG) was weighed out as listed in Table 1 (g/100 L water column). Treatments were applied using handheld Nylex ${ }^{\bullet}$ trigger sprayers that dispensed a fine mist and were calibrated individually to deliver $0.5 \mathrm{~mL} /$ puff. Two puffs were made targeting the wounds. In each plot, 40 picking wounds on spurs (20 either side of the plot) and 20 one-year-old shoots for rasp wound inoculations (10 either side of the plot) were chosen from different trees at random. Two rasp wounds per one-year-old shoot were made as described by Walter et al. (2016). Rasp wounds were included as additional wound controls. On 1 May 2018, in the morning, spurs and shoots were labelled with flagging tape and fruit were hand-picked and rasp wounds made (Walter et al. 2016). This was followed by inoculation with the $N$. ditissima conidium suspension $\left(1 \times 10^{5}\right.$ conidia $\left./ \mathrm{mL}\right)$ prepared in sterile distilled water in March 2018 from European canker lesions ('Scilate'), and stored frozen $\left(-18^{\circ} \mathrm{C}\right)$ in approximately $30 \mathrm{~mL}$ volumes in specimen jars (Orchard et al. 2018).

Disease symptoms were assessed five times on 5 July, 30 July, 28 August, 24 September and 
15 November 2018. Spurs and shoots showing European canker symptoms were cut and removed from the orchard. At the end of the experiment all inoculated plant material was removed from the orchard. No re-isolations of $N$. ditissima were undertaken.

\section{Captan residue analyses for both experiments}

Residue tests on excised leaf scars were undertaken to determine how much captan was applied to each wound. Non-inoculated and non-sprayed leaf scars (two shoots/ plot) were collected before treatment applications from the water control treatments. Two shoots per plot were also collected after all treatments (inoculation and captan sprays) were applied and spray had air-dried, providing 10 leaf scars/plot for residue analysis. Similarly, for the picking wounds, 10 spurs/plot were sampled from the water control plots before, and from all plots after, the inoculation and captan spray application. For the water treatment and $100 \%$ captan at field rate, an additional 10 picking scars were labelled but not inoculated, to determine captan residues with and without inoculum. No residue samples were taken from rasp wounds.

Leaf scars and picking wounds were excised on a plastic board covered with paper towels using a scalpel with a new blade. Leaf scars were excised by cutting the leaf scar in a $\mathrm{V}$-shape from the shoot (2-3 mm wide and deep). From the spur, only the terminal part $(2-3 \mathrm{~mm})$ of the fresh picking wound was cut. Excised tissues (10/plot) were then placed into a new glass scintillation vial and stored in the freezer $\left(-18^{\circ} \mathrm{C}\right)$. Between each plot sample, the paper towels were changed, gloves and the tools were cleaned with methylated spirit. Gloves were also changed after all replicates of one treatment were completed. All the sampling was done from low to high concentrations to avoid cross-contamination.

Captan concentration in each operational spray solution for both experiments was also determined before and after spraying. A subsample of each solution was stored at $-20^{\circ} \mathrm{C}$ prior to analysis. Residual captan was were analysed using gas chromatography mass spectrometry using single-ion monitoring and internal standard quantitation by Northcott Consultants Ltd as described in Gaskin et al. (2014).

\section{Statistical analyses}

Some initial analyses were carried out to assess whether there were any spatial trends (e.g. across tree rows, bays), and whether variation between plots was noticeably different from that within plots. Whilst there was some variation associated with bays for one or two of the variables, and more variation between plots than within plots, for simplicity, these effects were adjusted for by estimating over-dispersion in the model (GLM, McCullagh \& Nelder 1989).

The percentage of inoculated tissues (leaf scars, picking wounds, rasp wounds) developing symptoms was analysed with a binomial generalised linear model (GLM, McCullagh \& Nelder 1989) with a logit link. Earlier research has shown that shoot incidence and lesion incidence are always very highly correlated $(r>0.99$, Walter et al. 2015). Treatment effects were assessed both overall, and also, for the leaf-scar experiment, as a linear contrast of captan concentration. Since the trend is fitted on the logit scale, this means that on the percentage scale of the data, the trend is a non-linear function of captan concentration, constrained to give predictions between 0 and $100 \%$. For both trials, the treatment means, fitted curve, and associated 95\% confidence limits were obtained on the logit scale, and back-transformed for presentation.

The relationships between empirically determined captan amount, calculated captan in solution, average captan recovery from leaf scars, and the captan \% were explored using linear regression, with the line constrained to go through the origin. All analyses were carried out with GenStat (Payne et al. 2017).

\section{RESULTS}

\section{Captan residues in spray samples}

The empirically determined concentration of captan was very similar to the calculated theoretical concentration. Calculated and 
measured captan concentrations for either leafscar and picking wounds were very similar. Thus, only leaf-scar data are shown (Fig. 1).

The target concentration of captan in the dose-response treatment solutions was calculated on the basis that the $100 \%$ captan field rate treatment was prepared at the equivalent concentration of $27.8 \mathrm{~g}$ of captan in $10 \mathrm{~L}$ of water using a product with $90 \%$ ai, equivalent to $25.8 \mathrm{~g} / 10 \mathrm{~L}$. The concentration of captan in the remaining dose response treatment solutions was determined from this basis: $3 \times 25.8=77.4 \mathrm{~g} / 10 \mathrm{~L}$,

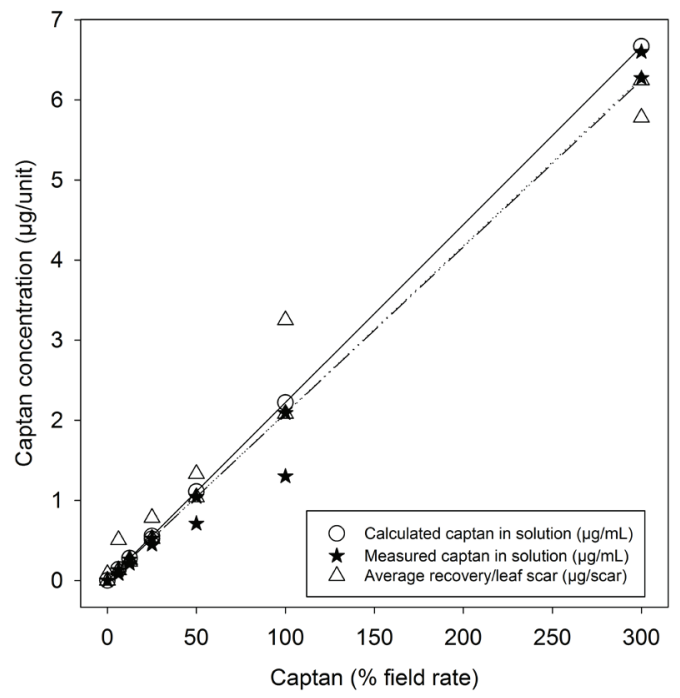

Figure 1 Average captan ( $\mu \mathrm{g} / \mathrm{unit})$ concentrations (day 0) after the spray application on 25 May 2015 applied to 'Royal Gala' trees. The treatment rate of $100 \%$ captan is equivalent to $1.3 \mathrm{~kg}$ active ingredient captan/ha, or 27.8 g Fruitfed Captan $80 \mathrm{WG}$, applied in $10 \mathrm{~L}$ of water to the young apple trees at $30-40 \%$ leaf fall. The measured captan concentrations $(\mu \mathrm{g} / \mathrm{mL})$ were based on three replicate subsamples. The leaf-scar data ( $\mu \mathrm{g} /$ leaf scar) are based on 475 leaf scars sampled, with leaf scars bulk analysed per replicate. For the regression the slope (S.E.) and $\mathrm{R}^{2}$ are, respectively:

Calculated captan: $0.022(>0.001)$ and 100

Measured captan: $\quad 0.021(0.001)$ and 97.4

Leaf scar captan: $\quad 0.021(0.002)$ and 92.8 etc. The measured concentration of captan in the treatment solutions was similar to the theoretical concentration although there was some variation as expected from this type of experiment (Fig. 1). The results demonstrate that an appropriate dose response range was achieved in the treatment solutions. There was also little difference between concentrations in the captan samples taken before or after spray application.

The different concentrations in the captan solutions were reflected in the average captan deposition on the leaf scars (Fig. 1). The variation amongst replicate samples was high, as would be expected in this type of field sample. However, average recovery per leaf scar followed a similar trend to the measured captan solution (Fig. 1).

\section{Lesion development from leaf scars}

The number of leaf scars showing symptoms was low, as was the case in 2015 (Dryden et al. 2016; Walter et al. 2017b). Only $7.9 \%$ of inoculated shoots expressed disease, with an average of 1.4 leaf scars/shoot developing symptoms. Percentage lesion expression decreased $(\mathrm{P}=0.001)$ with increasing captan rate. The data from the dose-response assay suggest that approximately $2 \mu \mathrm{g}$ captan/leaf scar (100\% field rate, Fig. $1 \& 2)$ is required to achieve maximum disease control.

\section{Lesion development from picking and rasp wounds}

For picking and rasp wounds, the percentage that developed European canker symptoms varied significantly between the treatments $(\mathrm{P}<0.001)$. The percentage decreased from a mean of $76 \%$ (Rasp) and 65\% (Picking) for the water treatment to below $30 \%$ for the highest captan rate (400\%). For both rasp and picking wounds, only the $400 \%$ captan treatment reduced the percentage of wounds with symptoms to less than half that seen in the water control (Fig. 3). The high correlation $(r=0.99)$ between the wound types for the infection levels at each captan dose is shown in Figure 3. This result indicates that rasp wounds could be used as a surrogate wound for product testing of picking wound protection. 


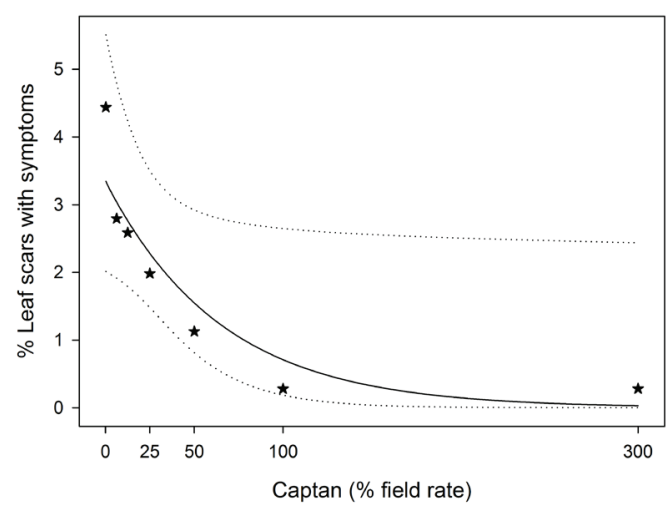

Figure 2 The percentage of inoculated 'Royal Gala' leaf scars expressing European canker symptoms (total from four assessments) in relation to the captan concentration used. The captan concentration of $100 \%$ is equivalent to 27.8 g Fruitfed Captan 80 WG applied in 10 litres of water to the young apple trees at $30-40 \%$ leaf fall. Leaf scars were artificially inoculated with Neonectria ditissima. Stars: mean percentage with symptoms; solid line: fitted dose-response curve; dotted lines: 95\% confidence limits for the fitted curve.

\section{DISCUSSION}

Increasing captan concentration increased the residues deposited onto leaf-scar wounds, as expected. The calculated captan concentration and the measured concentration in the spray solutions were similar (Fig. 1). Captan decay curves for the $100 \%$ field rate (data not shown) indicated that the captan residue concentrations declined from 9.7 to $0.7 \mu \mathrm{g} / \mathrm{scar}$ over a 5 -day rainfree period, indicating that repeat applications are required to maintain the level of residue required for control of $N$. ditissima infections. With a leaffall period of approximately six weeks, growers are encouraged to protect newly formed leaf scars through spraying before a rain event.

The disease data suggest that $>2 \mu \mathrm{g}$ of captan on leaf scars is required for optimal disease control. The knapsack mist-blower experiment indicated that a residue of $>2 \mu \mathrm{g}$ of captan per scar can be achieved on standard dwarf blocks with a captan ai application rate at approximately $2 \mathrm{~kg} /$

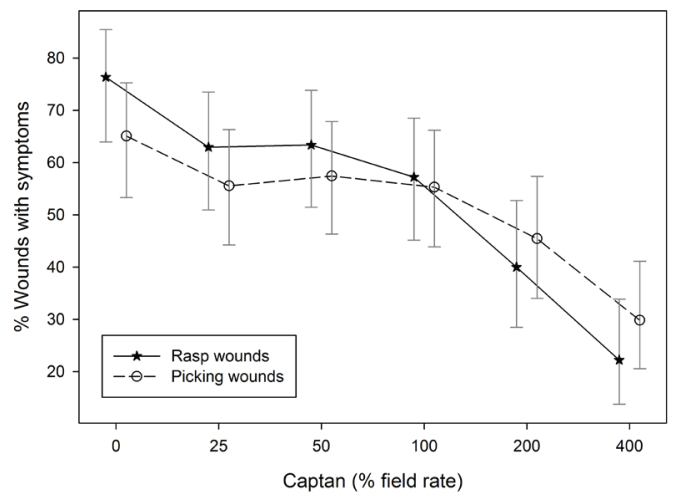

Figure 3 The percentage of inoculated 'Scilate' picking and rasp wounds expressing European canker symptoms (EC) in relation to the captan concentration used. Note that the data are jittered sideways slightly for clarity. The captan concentration of $100 \%$ is equivalent to $27.8 \mathrm{~g}$ Fruitfed Captan 80 WG applied in 10 litres of water to the young apple trees at harvest. The data are based on a total of 787 picking and 968 rasp wounds with four plots of seven trees per rate. Error bars are 95\% confidence limits.

ha. Parallel grower experiments on three sites (data not shown) indicated that this is generally achieved using standard orchard sprayers with water rates of $1000 \mathrm{~L} / \mathrm{ha}$. The low expression of leaf-scar infections is disappointing, but this has occurred in other artificially inoculated and naturally infected leaf-scar experiments in the 2015 autumn-winter period (Dryden et al. 2016; Walter et al. 2017b). Normally, under New Zealand (Tasman) conditions, we would expect $10-20 \%$ of leaf scars to develop symptoms within 6 months of artificial inoculation (Amponsah et al. 2015; Walter et al 2015; 2017b) but in the 2015 autumn-spring period only $4.4 \%$ of leaf scars expressed in the control treatment. This, however, was typical for the 2015 season (Dryden et al. 2016). Temperature was found to be the main driver for symptom development with rainfall frequency determining spore production potential (Beresford \& Kim 2011; Scheper et al. 2019). It is unlikely, that leaf-scar 
age played a role in the susceptibility to infection. Weber (2014) and Walter et al. (2015) showed that leaf-scar age $<2$ days did not affect disease development. The leaf scars inoculated here were 1-day-old. In contrast to the low disease expression of leaf scars, more than $60 \%$ of picking and rasp wounds developed symptoms, which was consistent with earlier work (Amponsah et al. 2015; Orchard et al. 2017; Walter et al. 2017b). Control of infection and disease development of these larger wounds was difficult to obtain. Only very high concentrations of captan $(400 \%$ field rate) provided a 55 and $70 \%$ disease reduction on picking and rasp wounds, respectively (Fig. 3). The industry does not recommend these high rates for captan applications and the rates studied here ( $>100 \%$ field rate) are outside the current registration for captan use in pipfruit.

Large wounds will be difficult to protect from $N$. ditissima with captan-based fungicides. The effect of wound size is in agreement with earlier work by Walter et al. (2016) showing that the larger the wound, the more infection will occur and the shorter the incubation and latent periods (infection to symptom expression and infection to spore production, respectively). A shorter latent period was also observed for picking and rasp wounds than for leaf scars, with disease assessments completed earlier for the former. This agrees with earlier work, where wound size and inoculum concentration determined the incubation period, i.e. the larger the wound and the more spores, the shorter the incubation period (Walter et al. 2016).

\section{CONCLUSIONS}

Wound protection of leaf scars was readily achieved using captan if applied at $2 \mathrm{~kg}$ (ai) captan in 1000 litres of water per hectare on trees produced on 'M9' dwarf rootstocks. Similar concentrations of captan have provided disease control under varying infection levels and disease risks under New Zealand conditions (Walter et al. 2015; Walter et al. 2017b). However, wound protection of larger wounds, such picking scars on spurs, is more difficult to obtain. The current recommendation for picking wound protection is to apply $2 \times 2 \mathrm{~kg}$ captan/ha in 2000 litres water per hectare achieved by double passing (rather than one single high volume spray). Double passing (in alternate directions) improves agrichemical deposition on hard to reach picking wounds (unpublished data). The effect of fungicides applied onto non-target areas (leaves, twigs and branches) in killing the spores as they are washed onto the target wounds (leaf scars, picking wounds) has not been studied. Similarly, the interaction between conidium concentration and captan concentration on large wounds requires further research.

\section{ACKNOWLEDGEMENTS}

This work was funded by New Zealand Apple \& Pear Inc. (formerly Pipfruit New Zealand Inc.), with co-funding from the Ministry for Primary Industries via the Sustainable Farming Fund (SFF404838). We thank Rachel Kilmister (New Zealand Apple \& Pear Inc.) for reviewing a draft of this manuscript.

\section{REFERENCES}

Alves SAM, Nunes CC 2017. Seasonal susceptibility of apple trees to Neonectria ditissima wound infections. New Zealand Plant Protection 70: 73-77.

Amponsah NT, Walter M, Beresford RM, Scheper RWA 2015. Seasonal wound presence and susceptibility to Neonectria ditissima infection in New Zealand apple trees. New Zealand Plant Protection 68: 250-256.

Beresford RM 2004. Benzimidazole management strategy. Pesticide Resistance Strategies. New Zealand Plant Protectin Society (Inc.). http:// resistance.nzpps.org/index/php?=fungicides/ benzimidazoles (accessed 4 April 2019).

Beresford RM, Kim KS 2011. Identification of regional climatic conditions favorable for development of European canker of apple. Phytopathology 101: 135-146.

Campbell RE, Roy S, Curnow T, Walter M 2016. Monitoring methods and spatial patterns of European canker disease in commercial orchards. New Zealand Plant Protection 69: 213-220. 
Dryden GH, Nelson MA, Smith JT, Walter M 2016. Postharvest foliar nitrogen applications increase Neonectria ditissima leaf scar infection in apple trees. New Zealand Plant Protection 69: 230-237.

Gaskin RE, Manktelow DWL, Northcott GL 2014. Effects of adjuvants on distribution and rainfastness of captan sprays on apple leaf scars to control European canker. New Zealand Plant Protection 67, 139-144.

Gordon E 2010. Captan and Folpet Chapter 90. In: Krieger R ed. Hayes' Handbook of Pesticide Toxicology (Third Edition). Academic Press Elsevier Inc. Pp. 1915-1945.

Grove GG 1997. Nectria canker. In: Jones AL, Aldwinckle HE eds. Compendium of apple and pear diseases. St Paul Minnesota, American Phytopathological Society. Pp. 35-36.

McCullagh P, Nelder JA 1989. Generalized Linear Models. Chapman \& Hall, London. 511 p.

Orchard S, Campbell RE, Turner L, Butler RC, Curnow T, Patrick E, Walter M 2018. Longterm deep-freeze storage of Neonectria ditissima conidium suspensions does not reduce their ability to infect apple trees. New Zealand Plant Protection 71: 158-165.

Payne R, Murray D, Baird D 2017. The Guide to the Genstat Command Language (Release 19). VSN International, Hemel Hempstead, Hertfordshire, UK.

Scheper RWA, Vorster L, Turner L, Campbell RE, Colhoun K, McArley D, Murti R, Hodson A, Beresford RM, Stock M, Fisher BM, Hedderly D, Walter M 2019. Lesion development and conidial production of Neonectria ditissima on apple trees in four New Zealand regions. New Zealand Plant Protection 72: 123-134.

Swinburne TR 1975. European canker of apple. Review of Plant Pathology 54: 787-799.

Walter M, Campbell RE, Amponsah NT, Scheper RWA, Butler RC 2017a. Evaluation of biological and agrichemical products for control of Neonectria ditissima conidia production. New Zealand Plant Protection 70: 87-96.

Walter M, Campbell RE, Amponsah NT, Turner
L, Rainham D, Kerer U, Butler RC 2017b. Can biological products control Neonectria ditissima apple wound infections? New Zealand Plant Protection 70: 63-72.

Walter M, Roy S, Fisher BM, Mackle L, Amponsah NT, Curnow T, Campbell RE, Braun P, Reinecke A, Scheper RWA. 2016. How many conidia are required for wound infection of apple plants by Neonectria ditissima? New Zealand Plant Protection 69: 238-245.

Walter M, Stevenson OD, Amponsah NT, Scheper RWA, Rainham D, Hornblow C, Kerer U, Dryden G, Latter I, Butler RC 2015. Control of Neonectria ditissima with copper based products in New Zealand. New Zealand Plant Protection 68: 241-249.

Weber RWS. 2014. Biology and control of the apple canker fungus Neonectria ditissima (syn. N. galligena) from a Northwestern European perspective. Erwerbs-Obstbau 56: 95-107.

Weber RWS, Palm G 2010. Resistance of storage rot fungi Neofabraea perennans, $N$. alba Glomerella acutata and Neonectria galligena against thophanate-methyl in Northern German apple production. Journal of Plant Diseases and Protection 117(4): 185-191. 